\title{
DNA DAMAGE IN TUMOR CELLS AND PERIPHERAL BLOOD LYMPHOCYTES OF ENDOMETRIAL CANCER PATIENTS ASSESSED BY THE COMET ASSAY
}

\author{
L.G. Buchynska ${ }^{1}$, O.V. Brieieva ${ }^{1,}$ *, N.P. Iurchenko', V.V. Protsenko ${ }^{1}$, S.V. Nespryadko ${ }^{2}$ \\ ${ }^{1}$ R.E. Kavetsky Institute of Experimental Pathology, Oncology and Radiobiology, NAS of Ukraine, \\ Kyiv 03022, Ukraine \\ ${ }^{2}$ National Cancer Institute, MH of Ukraine, Kyiv 03022, Ukraine
}

\begin{abstract}
To date, genome instability is considered to be a common feature not only of tumor cells, but also of non-malignant cells of cancer patients, including peripheral blood lymphocytes (PBLs). The issue of the association between genome instability in tumor cells and PBLs, as well as of its relationship with tumor progression remains poorly understood. Aim: To evaluate the level DNA damage in tumor cells and PBLs of endometrial cancer (EC) patients with regard to clinical and morphological characteristics of the patients. Materials and Methods: DNA damage was assessed in 106 PBLs samples and 42 samples of tumor cell suspension from EC patients by comet assay. PBLs from 30 healthy women were used as control. The level of DNA damage was expressed as the percentage of DNA in the comet tails (\% tail DNA). Results: It was revealed that the amount of DNA damage in PBLs of EC patients was 2.2 times higher in comparison with that of healthy donors $(8.3 \pm 0.7$ and $3.7 \pm 0.4 \%$ tail DNA, respectively) $(p<0.05)$. In this study, no association between the levels of DNA damage in endometrial tumor cells and PBLs was observed $(r=0.11 ; p>0.05)$. The amounts of DNA damage both in tumor cells and PBLs were not related to the degree of tumor differentiation as well as the depth of myometrial invasion, but depended on the body mass index (BMI) of EC patients: high level of lesions was observed in patients with elevated BMI values. Furthermore, the level of DNA damage in tumor cells was associated to familial aggregation of cancer and was significantly higher in endometrial cells from patients with family history of cancer vs that from EC patients with sporadic tumors $(32.3 \pm 2.9$ and $22.8 \pm 1.8 \%$ tail DNA, respectively $)(p<0.05)$. It was also found that for women who had high level of DNA damage in PBLs, the risk of EC was greater (odds ratio value of 3.5) compared to those with low level of such lesions. Conclusion: Genome instability that appears as an increased level of DNA damage in tumor cells and PBLs of EC patients is associated with BMI and family history of cancer and can reflect a predisposition to cancer.
\end{abstract}

Key Words: DNA damage, tumor cells, peripheral blood lymphocytes, endometrial cancer, comet assay.

Today, it is well known that the formation and progression of malignant neoplasms are accompanied by extensive molecular genetic changes. The presence of various types of DNA damage and chromosomal alterations is a characteristic feature of tumor cells [1]. According to modern notions, such changes are associated with genomic instability of malignant cells and reflect the influence of exo- and endogenous DNA-damaging factors, as well as defects in the functioning of the DNA repair systems $[1,2]$. Genome instability promotes the emergence of genetic diversity, clonal evolution of tumor cells and progression of the neoplastic process [3].

Modern studies indicate that endometrial carcinoma is characterized by the presence of microsatellite and chromosomal instability [4]. Moreover, endometrial cells are constantly exposed to the genotoxic influence of reactive oxygen species (ROS) resulting from metabolic transformations of estrogens during the menstrual cycle [5]. The elevated ROS level leads to the appearance of a highly mutagenic 8-oxo-7,8-dihydro-2'-deoxyguanosine, DNA breaks, apurin sites and chromosomal alterations [6]. Furthermore, genome instability of endometrial tumor cells may have hereditary origin, in particular due to germline mutations in the mismatch repair genes in the Lynch syndrome [7].

Submitted: October 04, 2017.

${ }^{\star}$ Correspondence: E-mail: olha.brie@gmail.com

Abbreviations used: BMI - body mass index; EC - endometrial cancer; PBLs - peripheral blood lymphocytes; ROS - reactive oxygen species.
In recent years, numerous studies have been devoted to the problem of genome destabilization in malignant cells $[8,9]$. However, today little is known about how the deregulation of genome integrity maintenance in carcinoma cells manifests at the systemic level, that is, on the structural and functional features of other cells in the body, including peripheral blood lymphocytes (PBLs). Meanwhile, in recent years, the issue of the possibility of using lymphocytes as surrogate markers (cells) that reflect the molecular genetic changes in the tumor is actively discussed [10-12].

A number of studies have shown that genome integrity in the PBLs of patients with different forms of cancer is disturbed [13-18]. Our previous study has revealed that PBLs of endometrial cancer (EC) are characterized by strong genome destabilization, in particular impaired DNA repair, which is associated with family history of cancer [21]. However, the issue of the relationship between genome instability in PBLs and tumor cells, as well as its association with tumor progression and clinical characteristics of patients with $E C$, remains insufficiently studied.

This study aims to analyze the association between DNA damage in PBLs and tumor cells of EC patients. In addition, the dependence of the degree of DNA damage on the clinical and morphological characteristics of patients and its significance to the risk of EC is studied.

\section{MATERIALS AND METHODS}

A total of 106 newly diagnosed, previously untreated patients with EC stages I and II were recruited 
for the study. All EC patients underwent surgery at the gynecological oncology department of the $\mathrm{Na}$ tional Cancer Institute, Kyiv, Ukraine. The mean age of EC patients was $59.1 \pm 1.6$ years. The control group consisted of 30 healthy women, matched on age and menopausal status, with no previous or present history of cancer. All patients were thoroughly informed about the study that was approved by the Committee for Ethical Issues of the R.E. Kavetsky Institute of Experimental Pathology, Oncology and Radiobiology, National Academy of Sciences of Ukraine.

Morphological analysis of tumors was performed on haematoxylin and eosin stained sections. All patients had a histologically confirmed diagnosis of endometrioid carcinoma. Information on family history of cancer was obtained through the personal interview of cancer was obtained through the pers

Lymphocytes were isolated from venous blood by density centrifugation using Ficoll-Hypaque gradient. To obtain tumor single cell suspensions, tumor tissue was disuupted with a MEDI machine (Becto Dickinson). After disaggregation of the tissue, thecell suspenionswerilted to removeany tissuedebris. The viability of PBLs and tumor cells was determined using the trypan blue exclusion test.

In order to evaluate baseline levels of DNA damage in PBLs and tumor cells, single cell gel electrophoresis assay (DNA comet assay) was performed as describe previously by Olive [22]. A suspension of lymphocytes or tumor cells $\left(1-2 \times 10^{5}\right.$ cells $\left./ \mathrm{ml}\right)$ was mixed with $1 \%$ low melting point agarose (Sigma-Aldrich) at $37^{\circ} \mathrm{C}$, and $75 \mu \mathrm{l}$ of this mixture was spread on slides precoated with $1 \%$ normal melting point agarose (Sigma-Aldrich). After solidification of the agarose, the slides were immersed into lysis solution $(2.5 \mathrm{M} \mathrm{NaCl}, 100 \mathrm{mM}$ EDTA $10 \mathrm{mM}$ Tris base, $10 \% \mathrm{DMSO}, 1 \%$ Triton X-100, $\mathrm{pH} 10$ ). Lymphocytes treated with $100 \mu \mathrm{M} \mathrm{H}_{2} \mathrm{O}_{2}$ for 5 min. at $4{ }^{\circ} \mathrm{C}$ were used as a positive control. The lysis was carried out in the dark for $1 \mathrm{~h}$ at $4{ }^{\circ} \mathrm{C}$. Then, the slides were transferred to the electrophoresis chamber and incubated in alkaline solution $(300 \mathrm{mM} \mathrm{NaOH}$ and $1 \mathrm{mM}$ EDTA, $\mathrm{pH}>13$ ) for $20 \mathrm{~min}$. Electrophoresis was performed in the same solution at a voltage of $0,8 \mathrm{~V} / \mathrm{cm}$ for $20 \mathrm{~min}$. After electrophoresis, the slides were neutralized with $0,4 \mathrm{M}$ Tris $\mathrm{HCl}$ solution for $10 \mathrm{~min}$ washed in distilled water 2 times for $5 \mathrm{~min}$ dried $37^{\circ} \mathrm{C}$, stained with SYBR Gren land ana 5 min with a fluor with a fluoscence microscope. A total of 50 micrographs per slidewere assessed using the CometScore sofware package (TriTek Corp.). The level of DNA damage was expressed as the percentage of DNA in the comet talls (\% tail DNA).

Statistical analysis was performed using the Statistica 8.0 software package (StatSoft, Inc.). The Mann -Whitney Uestwasused to evaluate differences between groups of EC patients and healthy women A $p$-value less than 0.05 was considered statistically significant. Relationship between variables was determined using Spearman's rank correlation coefficient $(r)$. Logistic regression was used to calculate odds ratios tion between DNA damage level in PBLs and EC risk.

\section{RESULTS}

Large inter-individual difference in the level of DNA damage in PBLs was observed in both healthy donors and EC patients. At the same time the range of this paramer tail DNA) than that of control samples (1.2-9.2\% DNA). On ava the level of DNA (am of EC patients was $8.3 \pm 0.7 \%$ til DNA that donors ( $3.7 \pm 0.4 \%$ tail DNA) ( $p<0.05$ ). Anee healthy devel $(3.7 \pm 0.4 \%$ tail DNA $(p<0.05)$. Analysis of the level of DNA damage in malignant cells was carried out on tumor tissue samples of $42 \mathrm{EC}$ patients $(7$ - well, 19-moderate and 16 - poorly differentiated tumors) It was revealed that $\mathrm{EC}$ cells are characterized by a pronounced amount of DNA damage, which averaged $26.4 \pm 1.8 \%$ tail DNA with individual variations ranging from 3.3 to $62.9 \%$ tail DNA (Fig. 1).

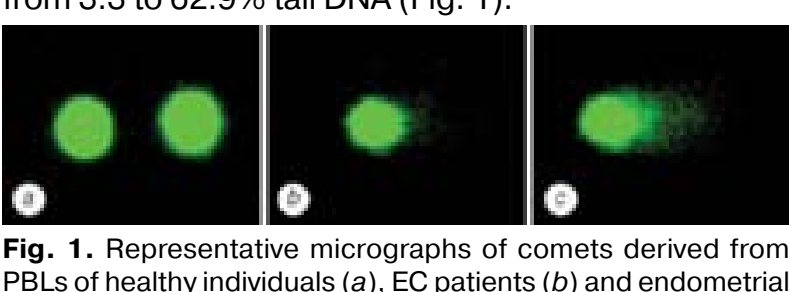
作 carcinoma cells $(c)$

To determine the possibility of using lymphocytes as surrogate cells that reflect certain characteristics of malignant cells, a correlation analysis was performed between the levels of DNA damage in PBLs and endometrial tumor cells. In this study, no association between these parameters was observed $(r=0.11 ; p>0.05)$. cinical and morphos Clinical and or tumor cells and the degree of tumor differintialion or well as the depth of myometria in However, it was found that the level of DNA dam 1). in both PBL was found that the level of DNA damage in bo (BMI) of EC patients. Thus, individue body mass index (BMI) of EC patients. Thus, individuals with BM values above the median $\left(>34.1 \mathrm{~kg} / \mathrm{m}^{2}\right)$ had significantly higher levels of DNAdamage than those with less obesity $\left(<34.1 \mathrm{~kg} / \mathrm{m}^{2}\right)(p<0.05)$ (Table 1). Therefore, increase DNA datients from obesity class I (BMI $31.0-35.9 \mathrm{~kg} / \mathrm{m}^{2}$ )

Table 1. Comparison of DNA damage in PBLs and tumor cells with clinical and morphological characteristics of EC patients

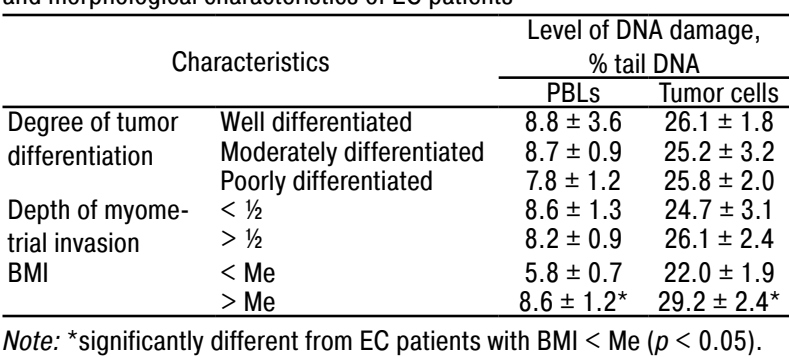

Pedigree analysis of all the EC patients revealed he familial clustering of cancers in 37 cases $(38.9 \%)$. Most often, first and second degree relatives of EC pa-

\section{Table 2. Familial aggregation of tumors in EC patients}

Degree of relationship

Encon

I(mother, father, sister, brother, children)
III (aunt, uncle, grandmother, grandfather, nephew, niece)

$4(5.4)$
$3(4.0)$

tients had tumors of the female reproductive system gastrointestinal tract and lungs (Table 2). For further analysis of DNA damage level in PBLs and tumor cells, a group of EC patients with family history of cancer was formed, which included women with clusterin of the female reproductive system and/or other Lynchassociated tumor incidence in their pedigrees [7].

There was no statistically significant difference

in the amount of DNA damage between PBLs from EC patients with family history of cancer compared to those with no family history. However, it was found that the level of DNA damage in tumor cells from patients with family history of cancer significantly patien $(32.3 \pm 2.9$ and $22.8 \pm 1.8 \%$ tail DNA, respectively) $(p<0.05)$ (Fig. 2).

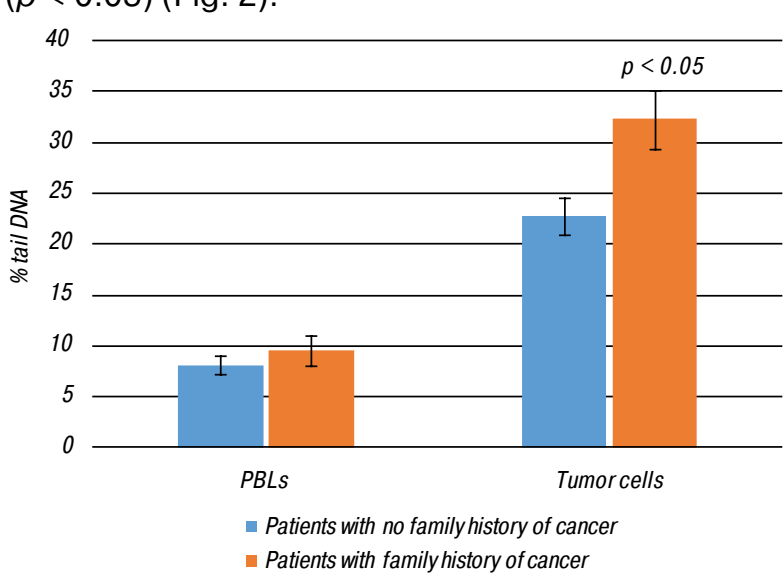

Fig. 2. DNA damage in PBLs and tumor cells of EC patients with

In order to assess the association between DNA damage level in $\mathrm{PBLs}$ and $\mathrm{EC}$ risk, the $\mathrm{OR}$ value among matched case and control groups (30 EC patients and 30 healthy individuals) was calculated. According to the obtained data, the median (Me) of \% tail DNA in PBLs was 3.7, on the basis of which all the examined women were divided into groups with high $(>\mathrm{Me})$ and low $(<\mathrm{Me})$ levels of DNA damage. It was found that for women who had high level of DNA damage in PBLs, the risk of $\mathrm{EC}$ was greater compared to those with low level of such lesions (OR value of 3.5) (Table 3).

\begin{tabular}{|c|c|c|c|}
\hline $\begin{array}{c}\begin{array}{c}\text { Level of DNA } \\
\text { damage }\end{array} \\
\text { (a) }\end{array}$ & $\begin{array}{c}\text { Group of exa } \\
\text { EC patients }\end{array}$ & $\frac{\text { ned women }}{\text { Controls }}$ & OR $(95 \%$ Cl) \\
\hline $\begin{array}{l}\text { Low } \\
\text { Hiag h }\end{array}$ & $\begin{array}{l}11 \\
19\end{array}$ & $\begin{array}{l}10 \\
20\end{array}$ & $3.5(1.2-10.0)$ \\
\hline
\end{tabular}

DISCUSSION

The issue of the occurrence and causes of genome instability in PBLs of cancer patients has been actively investigated over recent years. Results of several studies indicate a significant destabilization of the genome in PBLs of cancer patients. In particular, high (in patients 作, (13-20]. A number of DNA damage in PBLs and risk of cancer $[19,20]$ th is believed that an increased level of DNA damage in PBLs and malignant cells may be caused by influence of environmental genotoxic factors as well as substances released during metabolic processes in cancer patients [2]. Very often, the effect of such actors emerges through the action of ROS that combined with antioxidant system failure, leads to the development of oxidative stress [6]. It is well-known that OSOS are che ox red by pronounced DNA-cameing properties. Theycan induce the appearance of single8-0xo-7 8-dihydro-2'-deoxyguanosine and other 8-ox-7,8-dihydro-2'-deoxygu nosine and other nexo f the possibementis oxidative DNA damage caused by ROS is constantly detected in malignant neoplasms of various localizations [23]

It is supposed that the main sources of endogenous ROS are the reactions of cellular respiration, lipid peroxidation and inflammation. Along with the latter the metabolic transformations of estrogens may have a strong influence on the development of genome instability in PBLs and tumor cells in EC patients, since these processes are accompanied by the formation of genotoxic intermediates - catechol estrogens, quinones and semiquinones which can directly bind DNA, leading to the occurrence of apurinic sites, or enter the redox reactions with ROS production [26-28]. It is possible that the high level of DNA damage in PBLs and tumor cells of EC patients with elevated $B M I$ values may be associated with hormonal effects as far as adipose tissue is an important source of esrogen. In addition, elevated BMI values are related increas okines (TNFa, L-1, L- 6 , etc.) that can induce ROS ormation [29]. It is characteristic that Salinas et al. (eved an ex ers in the blood of EC patients with an increased BMI value [30].

An increased level of DNA damage in tumor cells in EC patients with family history of cancer can be caused by hereditary defects in DNA repair genes and tumor suppressors [7, 31-33]. Furthermore it is assumed that there are other molecular mechanisms that determine hereditary predisposition to $\mathrm{EC}$ which may also be associated with the development of genome instability [32, 33]. Thus, it was found that the risk of developing hormone-dependent tumors 
depends on the polymorphism of the genes involved in the estrogen metabolism $[34,35]$. According to Santos et al., some polymorphic variants of such genes can modulate the level of chromosomal instability in PBLs of cancer patients [35].

It should be noted that the issue of the underlying causes of genome instability in cells of cancer patients remains open today. There is an opinion that genome instability can precede tumorigenesis as well as it may be the consequence of this process. Actually, the development of a malignant disease may enhance the level of pre-existing genome destabilization in non-malignantcells through the effect of genotoxic substances relosed substances reans

In conclusion, the results of the study indicate a pronounced destabilization of the genome in PBLs and tumor cells of EC patients, which may reflect homeostasis disorders in these women. It was shown that in both PBLs and tumor cells, the level of DNA damage depends on the BMI of EC patients and increases in cases with elevated values of this parameter. In addition, the dependence of the level of DNA damage in endometrial carcinoma cells on familia aggregation of cancers was detected: the amount of DNA lesions was higher in EC patients with family history of cancer. The presented data indicate the possibility of determining the risk of EC by DNA damage level in PBLs. Specifically, the high amount of baseline DNA damage in PBLs is associated with an increase risk of EC. Further studies of PBLs of cancer patients are needed in order to determine the role of genome instability of somatic non-malignant cells in the pathogenesis of the malignant disease. It is equally impor tant to ascertain the possibility of using lymphocytes as surrogate cells that reflect the morphological and functional characteristics of tumor cells.

\section{REFERENCES}

1. Shen Z. Genomic instability and cancer: an introduction. J Mol Cell Biol 2011; 3: 1-3.

2. Langie SA, Koppen G, Desaulniers D, et al. Causes of genome instability: the effect of low dose chemical exposures in modern society. Carcinogenesis 2015; 36: S61-88.

3. Hanahan D, Weinberg RA. Hallmarks of cancer: the next generation. Cell 2011; 144: 646-4.

4. Cancer Genome Atlas Research Network. Integrated genomic characterization of endometrial carcinoma. Nature 5. Sugino N.

5. Sugino $\mathrm{N}$. The role of oxygen radical-mediated signaling pathways in endometrial function. Placenta 2007; 28 (Sup

6. Oxidative stress and inflammation in non-communicable diseases - molecular mechanisms and perspectives in therapeutics. J Camps, eds. New York, NY: Springer Berli Heidelberg; 2014. $223 \mathrm{p}$.

7. Committee on Practice Bulletins-Gynecology; Society of Gynecologic Oncology. ACOG Practice Bulletin No. 147: Lynch syndrome. Obstet Gynecol 2014; 124: 1042-54.

8. Kandoth C, McLellan MD, Vandin F, et al. Mutational landscape and significance across 12 major cancer types. Nature 2013; 502: 333-9.
9. Martincorena I, Campbell PJ. Somatic mutation in canand normal cells. Science 2015; 349: 1483-9.

10. Herrera M, Dominguez G, Garcia JM, et al. Differences in repair of DNA cross-links between lymphocytes

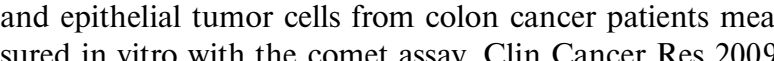
sured in vitro with the comet assay. Clin Cancer Res 2009;

11. Zhang YY, Gu KS. DNA repair capacity in periphera blood lymphocytes predicts efficacy of platinum-based chemotherapy in patients with gastric cancer. Asian Pac J Cancer

12. Buchynska LG, Brieieva OV, Nesina IP, et al. Pecu12.ities of DNA repair in peripheral blood lymphocytes an tumor tissue of endometrial cancer patients. Oncology (Ukr) 2016; 18: 300-4 (in Ukrainian)

13. Santos RA, Teixeira AC, Mayorano MB, et al. Basa levels of DNA damage detected by micronuclei and come assays in untreated breast cancer patients and healthy women. Clin Exp Med 2010; 10: 87-92.

14. Synowiec E, Stefanska J, Morawiec Z, et al. Association between DNA damage, DNArepairgenes valiability an clinical characteristics in breast cancer patients. Mutat Res 2008; 648: 65-72.

15. Stefanou DT, Bamias A, Episkopou H, et al. Aberran DNA damage response pathways may predict the outcome of platinum chemotherapy in ovarian cancer. PLoS One 2015; 10: e0117654.

16. Shahidi M, Mozdarani H, MuellerWU. Radiosensitivity sporadic pretes or gamma-irradiated leukocytes from assessed by alkaline comet assay. Iran Biomed J 2010; 14: $67-75$.

17. Lou J, He J, Zheng W, et al. Investigating the genetic instability in the peripheral lymphocytes of 36 untreated lung cancer patients with comet assay and micronucleus assay. Mutat Res 2007; 617: 104-10

18. Vasavi M, Vedicherala B, Vattam KK, et al. Assessment of genetic damage in inflammatory, precancerous, an cancerous pathologies of the esophagus using the comet assay. Genet Test Mol Biomarkers 2010; 14: 477-82.

19. Schabath MB, Spitz MR, Grossman HB, et al. Genetic instability in bladder cancer assessed by the comet assay. J Nat Cancer Inst 2003; 95: 540-7.

20. Lin X, Wood CG, Shao L, et al. Risk assessmen of renal cell carcinoma using alkaline comet assay. Cancer ; 110: $282-8$.

21. Buchynska LG, Brieieva OV, Glushchenko NP, et al. DNA repair deficiency in peripheral blood lymphocytes of endometrial cancer patients with a family history of cancer. BMC ancer 2014; 14: 765.

22. Olive PL, Banath JP. The comet assay: a metho to measur $23-9$.

23. Kryston TB, Georgiev AB, Pissis P, et al. Role of oxidative stress and DNA damage in human carcinogenesis. Mutat es 2011; 711: 193-201.

24. Martin OA, Redon CE, Nakamura AJ, et al. Systemic 25. Mittra I, Samant U, Sharma S, et al. Cell-free chromain from dying cancer cells integrate into genomes of bystande healthy cells to induce DNA damage and inflammation. Cell Death Discov 2017; 3: 17015.

26. Bolton JL, Thatcher GR. Potential mechanisms 21: $93-101$
27. Samavat H, Kurzer MS. Estrogen metabolism and breast cancer. Cancer Lett 2015; 356: $231-43$.

28. Tsuchiya Y, Nakajima M, Yokoi T. Cytochrome P450mediated metabolism of estrogens and its regulation in human.

29. Halliwell B, Gutteridge JMC. Free radicals in biology and $\mathrm{m}$

30. Salinas EA, Wernimonta SA, Mapuskara KA, et al. Oxidative stress biomarkers and risk of endometrial cancer. Gynecol Oncol 2015; 137: 160.

31. Wong A, Ngeow J. Hereditary syndromes manifesting as endometrial carcinoma: how can pathological features aid risk assessment? BioMed Research Int 2015; Article ID 219012: $17 \mathrm{p}$
32. Bharati R, Jenkins MA, Lindor NM, et al. Does risk of endometrial cancer for women without a germline mutaon in a DNA mismatch repair gene depend on family history fondometrial cancer or colorectal cancer? Gynecol Onco

33. Buchynska LG, Brieieva OV, Nekrasov KA et al. The family history of cencer. Exp Oncol 2015; 37: 272-6.

34. Liu JY Yang Y, Liu ZZ, et al. Association between the CYP1B1 polymorphisms and risk of cancer: a meta-analysis. Mol Genet Genomics 2015; 290: 739-65.

35. dos Santos RA, Teixeira AC, Mayorano MB, et al. Variability in estrogen-metabolizing genes and their association with genomic instability in untreated breast cancer patienand healthy women. J Biomed Biotechnol 2011; 2011: 571784. 